\title{
CDKN2A-rs10811661 polymorphism, waist-hip ratio, systolic blood pressure, and dyslipidemia are the independent risk factors for prediabetes in a Vietnamese population
}

\author{
Tran Quang Binh ${ }^{{ }^{*}}$, Nguyen Thi Trung Thu², Pham Tran Phuong ${ }^{1}$, Bui Thi Nhung ${ }^{3}$ and Trinh Thi Hong Nhung ${ }^{1}$
}

\begin{abstract}
Background: People with prediabetes are at greater risk for heart attack, stroke, kidney disease, vision problems, nerve damage and high blood pressure, compared to those without the disease. Prediabetes is a complex disorder involving both genetic and environmental factors in its pathogenesis. This cross-sectional study aimed to investigate the independent risk factors for prediabetes, considering the contribution of genetic factors (TCF7L2-rs7903146, IRS1-rs1801278, INSR-rs3745551, CDKN2A-rs10811661, and FTO-rs9939609), socio-economic status, and lifestyle factors.

Results: Among the candidate genes studied, the CDKN2A-rs10811661 polymorphism was found to be the most significant factor associated with prediabetes in the model unadjusted and adjusted for age, sex, obesity-related traits, systolic blood pressure, dyslipidemia, socio-economic status, and lifestyle factors. In the final model, the CDKN2A-rs10811661 polymorphism (OR per T allele $=1.22,95 \% \mathrm{Cl}=1.04-1.44, P=0.017$ ), systolic blood pressure (OR per $10 \mathrm{mmHg}=1.14,95 \% \mathrm{Cl}=1.08-1.20, P<0.0001)$, waist-hip ratio $(\mathrm{OR}=1.25,95 \% \mathrm{Cl}=1.10-1.42, P<0.0001)$, dyslipidemia $(\mathrm{OR}=1.57,95 \% \mathrm{Cl}=1.15-2.14, P=0.004)$, and residence $(\mathrm{OR}=1.93,95 \% \mathrm{Cl}=2.82-4.14, P<0.0001)$ were the most significant independent predictors of prediabetes, in which the power of the adjusted prediction model was 0.646 .
\end{abstract}

Conclusions: The study suggested that the CDKN2A-rs10811661 polymorphism, waist-hip ratio, systolic blood pressure, and dyslipidemia were significantly associated with the increased risk of prediabetes in a Vietnamese population. The studied genetic variant had a small effect on prediabetes.

Keywords: Association study, CDKN2A gene, Prediabetes, Single nucleotide polymorphism, Vietnamese population

\section{Background}

Prediabetes is the condition where blood sugar levels are higher than normal, but not yet high enough to be classified as diabetes [1]. The importance of prediabetes has been underscored by the facts that (i) up to $70 \%$ of people with prediabetes may develop type 2 diabetes (T2D) during their lifetimes [2]; (ii) the average time it takes a person with prediabetes to develop T2D is 3 years [3]; and (iii) people with prediabetes are at greater risk for heart attack, stroke, kidney disease, vision

\footnotetext{
* Correspondence: binhtq@nihe.org.vn

'National Institute of Hygiene and Epidemiology, 1 Yersin, Hanoi 112800, Vietnam

Full list of author information is available at the end of the article
}

problems, nerve damage and high blood pressure, compared to people without the disease $[4,5]$. However, prediabetes is reversible and its related metabolic disorders can be improved with proper treatment [6]. Thus, it is crucial to identify risk factors for prediabetes to prevent a person from developing this disorder.

Predisposition to prediabetes could be determined by many different combinations of genetic variants and environmental factors. Environmental factors that can increase risk for prediabetes and T2D include lifestyle habits (a sedentary lifestyle and poor nutrition, smoking and excessive alcohol consumption), overweight or obese, poor sleep, age, high blood pressure, and abnormal lipid levels $[7,8]$. Genetic factors contribute to development of 
prediabetes and T2D. Defects in genes that encode proteins affect pathways involved in insulin control and glucose homeostasis (the balance of insulin and the hormone glucagon to maintain blood glucose), hence can raise the risk for diabetes. Such genes including INSR, IRS1, CDKN2A, TCF7L2, and FTO are also identified in genome wide association (GWA) studies $[9,10]$. The contributions of these genetic variants on T2D vary among different ethnic populations because of the differences in environmental factors, risk-factor profiles, and genetic background $[8,11]$. It is unclear whether these variants have the same effect in Vietnamese population, which has different socio-economic and genetic background. Moreover, the importance of each risk factor for prediabetes which varies within a specific population needs to be clarified. To date, there has been a limited data on risk factors for prediabetes in Vietnamese population. Therefore, the study was designed to investigate both genetic (TCF7L2-rs7903146, IRS1-rs1801278, INSR-rs3745551, CDKN2A-rs10811661, and FTO-rs9939609) and environmental factors for prediabetes in a Vietnamese population. The most significant factors associated with prediabetes were also reported.

\section{Methods}

\section{Subjects and data collection}

The study included 2,610 subjects (411 prediabetic cases and 2,199 normoglycemic controls). They were recruited from a cross-sectional and population-based study to be representatives of prediabetic subjects and normoglycemic controls in the general population of the Red River Delta, Vietnam. Of the total 2,610 participants, 2,608 (99.9 \%) belonged to Kinh ethnic group. The Ethics Committee of the National Institute of Hygiene and Epidemiology, Vietnam approved the study. All participants provided written informed consent before entering the study. The details of the survey to collect data were reported previously [12]. In summary, data were collected on social-economic status (current age, gender, ethnicity, educational level, occupation, marital status, income level), lifestyle patterns (residence, alcohol consumption, smoking history, time spent for night's sleep, siesta, and watching television), family history of diabetes, medical and reproductive history. Anthropometric parameters measured included weight, height, waist circumference (WC), hip circumference (HC), percent body fat, systolic blood pressure (SBP), and diastolic blood pressure (DBP). Blood samples were collected and centrifuged immediately in the morning after a participant had fasted for at least $8 \mathrm{~h}$ prior to the clinic visit. Plasma glucose was measured by glucose oxidase method (GOD-PAP). Lipid profile including total cholesterol (TC), triglycerides (TG), high-density lipoprotein cholesterol (HDL-C), and low-density lipoprotein cholesterol (LDL-C) were measured by enzymatic methods.
Glucose and lipid profile were analyzed using a semiautoanalyzer (Screen Master Lab; Hospitex Diagnostics LIHD112, Italy) with commercial kit (Chema. Diagnostica, Italy). Dyslipidemia [13] is defined as $\mathrm{HDL}-\mathrm{C}<40 \mathrm{mg} / \mathrm{dL}$ for men and $<50 \mathrm{mg} / \mathrm{dL}$ for women, and TC, LDL-C and TG levels $\geq 200, \geq 130$ and $\geq 130 \mathrm{mg} / \mathrm{dL}$, respectively.

The glycaemic status of subjects was determined using fasting plasma glucose level (FPG) and oral glucose tolerance test (OGTT) with $75 \mathrm{~g}$ glucose [14]. Participants were classified as having diabetes if they had FPG $\geq 7.0 \mathrm{mmol} / \mathrm{l}$ or 2-h plasma glucose $\geq 11.1 \mathrm{mmol} / \mathrm{l}$ or previous diagnosis of diabetes and current use of drug for its treatment. Normal glucose tolerance (NGT) was classified when FPG $<5.6 \mathrm{mmol} / \mathrm{l}$ and 2-h plasma glucose $<7.8 \mathrm{mmol} / \mathrm{l}$. Isolated impaired fasting glucose (IFG) was identified if FPG was between 5.6 and $6.9 \mathrm{mmol} / \mathrm{l}$, and 2-h plasma glucose was less than $7.8 \mathrm{mmol} / \mathrm{l}$. Isolated impaired glucose tolerance (IGT) was classified if FPG was less than $5.6 \mathrm{mmol} / \mathrm{l}$ and 2-h plasma glucose was between 7.8 and $11.0 \mathrm{mmol} / \mathrm{l}$. Combined IFG and IGT (IFG - IGT) were determined if FPG was between 5.6 and $6.9 \mathrm{mmol} / \mathrm{l}$, and 2-h plasma glucose was between 7.8 and $11.0 \mathrm{mmol} / \mathrm{l}$. Prediabetic status included IFG and/or IGT.

\section{Genotyping}

Peripheral blood samples were obtained from each participant and genomic DNA was extracted from peripheral blood leukocytes, using Wizard ${ }^{\circ}$ Genomic DNA Purification Kit (Promega Corporation, USA). Primers, protocols of polymerase chain reaction, and restriction enzymes for genotyping the polymorphisms are presented in Additional file 1. Our typing strategy was to use the allele-specific primer (ASP) typing method [15], then $10 \%$ of all samples were typed using restriction fragment length polymorphism (RFLP) analysis to validate observed results. There were more than $98 \%$ agreement of the result between ASP typing method and RFLP analysis in the samples checked. In addition, samples were selected randomly and re-genotyped using the original platform. The results showed that the concordance rate was 96-99\% with respect to the $30 \%$ of samples genotyped twice for quality control.

\section{Statistical analysis}

Genotypes were coded as 0,1 , and 2, depending on the number of copies of risk alleles. Genotype frequencies were compared and tested for Hardy-Weinberg equilibrium (HWE) by Fisher's exact test. Five genetic models were tested (dominant, co-dominant, over-dominant, recessive, and additive model). Akaike's Information Criterion and Bayesian Information Criterion were applied to estimate the best-fit model for each SNP. The procedure was performed in SNPstat software [16]. 
Quantitative variables were checked for normal distribution and compared using Mann-Whitney $U$ test. Binary logistic regression analysis was used to test several models for the associations of prediabetes with the risk alleles and other variables, taken into account the covariates (age, sex, socio-economic status, lifestyle factors, obesity-related traits (BMI, WC, HC, WHR, and percent body fat), systolic blood pressure, and lipid profile). The variables included in the analyses were checked for multicollinearity to ensure the stability of the parameter estimates. Here, data are presented as odds ratios with $95 \%$ confidence intervals (CI). In order to assess the model performance, a receiver operating characteristic (ROC) curve was built to plot probabilities resulted from the multivariate logistic regression analysis, and the area under ROC curve (AUC) was used to measure the power to predict individuals with prediabetes. The level of significance was set to 0.05 for all analyses. The above statistical procedures were performed using SPSS version 16.0 (SPSS, Chicago, USA). The Bayesian model averaging was used to cross-validate the final model using Bayesian Model Averaging Software with the $R$ Statistical Environment version 3.1.3 [17].

\section{Results}

\section{Characteristics of the study subjects}

Of the 2,610 participants recruited into the study, $65.4 \%$ were women, $72.6 \%$ were farmers, and $72.2 \%$ had elementary or intermediate levels of education. The characteristics of subjects in prediabetic cases and controls are shown in Table 1 . There were significant differences between prediabetic and control groups in age, BMI, waist circumference, WHR, systolic blood pressure, diastolic blood pressure, total cholesterol, $\mathrm{HDL}-\mathrm{C}$, and triglyceride. Significant differences between cases and controls were not found in gender, height, weight, body fat percent, hip circumference, nutrition status, and LDL - C.

\section{Associated factors for prediabetes}

Socioeconomic status (age, marital status), lifestyle patterns (residence, alcohol consumption), anthropometric traits (BMI, WC, WHR, and SBP), and lipid profile (TC, TG, and LDL-C) were significantly associated with prediabetes in univariate logistic regression (Additional file 2). The analysis of the best-fit model for individual SNPs in candidate genes with prediabetes among genetic models of inheritance (additive, codominant, dominant, overdominant,

Table 1 Characteristics of subjects in prediabetic cases and controls

\begin{tabular}{|c|c|c|c|c|}
\hline Characteristics & $\begin{array}{l}\text { Prediabetic cases } \\
(N=411)\end{array}$ & $\begin{array}{l}\text { Controls } \\
(N=2199)\end{array}$ & $\begin{array}{l}\text { Total } \\
(N=2610)\end{array}$ & $P$-value \\
\hline Male, $n(\%)$ & $152(37 \%)$ & $752(34.2 \%)$ & $904(34.6 \%)$ & 0.276 \\
\hline Age (year) & $53(47-57.8)$ & $51(46-56)$ & $51(46-56)$ & $<0.0001$ \\
\hline Weight (kg) & $51.8(46-57.9)$ & $51(46.3-56.5)$ & $51(46.2-56.6)$ & 0.117 \\
\hline Height (cm) & $155.5(150.5-160)$ & $155(150.7-160)$ & $155(150.6-160$ & 0.731 \\
\hline Body mass index $\left(\mathrm{kg} / \mathrm{m}^{2}\right)$ & $21.5(19.6-23.4)$ & $21.1(19.3-22.9)$ & $21.2(19.4-23)$ & 0.012 \\
\hline Body fat (\%) & $28.2(23.7-31.9)$ & $27.5(22.9-31.5)$ & $27.6(23.2-31.6)$ & 0.119 \\
\hline Waist circumference (cm) & $75(69-82)$ & $73.5(68.5-79)$ & $74(68.5-79.5)$ & 0.002 \\
\hline Hip circumference $(\mathrm{cm})$ & $88(84-92)$ & $88(84-91.3)$ & $88(84-91.5)$ & 0.628 \\
\hline Waist - hip ratio & $0.85(81-0.90)$ & $0.84(0.80-0.88)$ & $0.84(0.80-0.88)$ & $<0.0001$ \\
\hline \multicolumn{5}{|l|}{ Nutrition status } \\
\hline Normal & $237(57.8)$ & $1342(61.4)$ & $1579(60.8)$ & \multirow[t]{4}{*}{0.129} \\
\hline Overweight & $77(18.8)$ & $344(15.7)$ & $421(16.2)$ & \\
\hline Obesity & $44(10.7)$ & $183(8.4)$ & $227(8.7)$ & \\
\hline Underweight & $52(12.7)$ & $316(14.5)$ & $368(14.2)$ & \\
\hline Systolic blood pressure (mmHg) & $120(110-137.5)$ & $110.3(100-127.5)$ & $115(110-130)$ & $<0.0001$ \\
\hline Diastolic blood pressure $(\mathrm{mmHg})$ & $80(70-85)$ & $70(65-80)$ & $70(65-80)$ & $<0.0001$ \\
\hline Total cholesterol $\left(\mathrm{mmol} \mathrm{I}^{-1}\right)$ & $4.60(4.09-5.00)$ & $4.20(3.85-4.87)$ & $4.30(3.90-4.90)$ & $<0.0001$ \\
\hline $\left.\mathrm{HDL}-\mathrm{C}(\mathrm{mmol} \mathrm{I})^{-1}\right)$ & $1.19(0.97-1.60)$ & $1.23(0.99-1.60)$ & $1.22(0.98-1.60)$ & $<0.0001$ \\
\hline $\mathrm{LDL}-\mathrm{C}\left(\mathrm{mmol} \mathrm{I} \mathrm{I}^{-1}\right)$ & $3.10(2.64-3.70)$ & $2.79(2.31-3.31)$ & $2.83(2.34-3.40)$ & 0.103 \\
\hline Triglyceride $\left(\mathrm{mmol} \mathrm{I^{-1 } )}\right.$ & $1.80(1.12-2.55)$ & $1.34(1.00-2.02)$ & $1.41(1.01-2.10)$ & $<0.0001$ \\
\hline
\end{tabular}

$\mathrm{HDL}-\mathrm{C}$, high-density lipoprotein - cholesterol; LDL - C, low-density lipoprotein - cholesterol. Quantitative data are median (interquartile range). Qualitative data are number (\%). P-value by Mann-Whitney $U$ test or chi-square test 
and recessive) is shown in Additional file 3. The lowest values of both Akaike's Information Criterion and Bayesian Information Criterion were only found in the additive model, indicating this best-fit model in all studied SNPs.

The association of prediabetes with residence, marital status, alcohol consumption, WHR, SBP, dyslipidemia, and CDKN2A-rs10811661 polymorphism was observed in multivariate analysis (Table 2), considering the contribution of genetic factors, anthropometric measurements, lipid profile, socio-economic status and lifestyle factors. The prediction model using the most significant predictors of prediabetes is presented in
Table 3. In the final model, the CDKN2A-rs10811661 polymorphism (OR per $\mathrm{T}$ allele $=1.22$, $95 \% \mathrm{CI}=1.04-$ 1.44, $P=0.017$ ), systolic blood pressure (OR per $10 \mathrm{mmHg}=1.14,95 \% \mathrm{CI}=1.08-1.20, P<0.0001)$, waist hip ratio $(\mathrm{OR}=1.25,95 \% \mathrm{CI}=1.10-1.42, P<0.0001)$, dyslipidemia $(\mathrm{OR}=1.57,95 \% \mathrm{CI}=1.15-2.14, P=0.004)$, and residence $(\mathrm{OR}=1.93,95 \% \mathrm{CI}=2.82-4.14, \quad P<0.0001)$ were the most significant independent predictors of prediabetes. The independent variables in the final model were also confirmed using the Bayesian model averaging (Additional file 4). The area under ROC curve for the prediction model of prediabetes on the predictors including

Table 2 Multivariate analysis of association for prediabetes

\begin{tabular}{|c|c|c|c|c|c|}
\hline Variable & OR $(95 \% \mathrm{Cl})$ & $P$-value & Variable & OR $(95 \% \mathrm{Cl})$ & $P$-value \\
\hline Sex & & & Residence & & \\
\hline Female & 1 & & Rural & 1 & \\
\hline Male & $0.78(0.45-1.33)$ & 0.354 & Urban & $3.95(2.50-6.23)$ & $<0.0001$ \\
\hline Age (year) & $1.02(0.99-1.04)$ & 0.075 & Alcohol consumption & & \\
\hline Marital status & & & None & 1 & \\
\hline Married & 1 & & $<1 \mathrm{drink} / \mathrm{mo}$ & $1.14(0.62-2.09)$ & 0.686 \\
\hline Never & $2.14(1.01-4.55)$ & 0.048 & $\geq 1 \mathrm{drink} / \mathrm{mo}$ to $<1 \mathrm{drink} / \mathrm{wk}$ & $2.02(1.15-3.56)$ & 0.015 \\
\hline Widowed & $0.92(0.53-1.60)$ & 0.766 & $1 \mathrm{drink} / \mathrm{wk}$ to $\leq 1 \mathrm{drink} / \mathrm{d}$ & $1.49(0.87-2.55)$ & 0.147 \\
\hline Others & $0.87(0.29-2.57)$ & 0.800 & $\geq 2 \mathrm{drink} / \mathrm{d}$ & $2.06(1.16-3.68)$ & 0.014 \\
\hline Education level & & & Smoking & & \\
\hline Elementary & 1 & & None & 1 & \\
\hline Intermediate & $0.97(0.63-1.50)$ & 0.904 & Current smoker & $0.75(0.44-1.28)$ & 0.293 \\
\hline Secondary & $0.99(0.56-1.76)$ & 0.987 & Ex-smoker & $1.01(0.57-1.77)$ & 0.987 \\
\hline Post-secondary & $0.89(0.48-1.62)$ & 0.691 & Watching televison time/day & & \\
\hline Heavy occupation & & & $\leq 3 \mathrm{~h}$ & 1 & \\
\hline Yes & 1 & & $>3 \mathrm{~h}$ & $0.81(0.44-1.51)$ & 0.513 \\
\hline No & $0.95(0.64-1.41)$ & 0.800 & Sleeping time/day & & \\
\hline Income level & & & $6-7 \mathrm{~h}$ & 1 & \\
\hline$<25$ percentiles & 1 & & $<6 \mathrm{~h}$ & $0.90(0.62-1.31)$ & 0.584 \\
\hline $25-<50$ percentiles & $1.25(0.86-1.82)$ & 0.246 & $\geq 8 \mathrm{~h}$ & $0.99(0.72-1.39)$ & 0.996 \\
\hline $50-75<$ percentiles & $0.94(0.63-1.40)$ & 0.749 & Sitting time/day & & \\
\hline \multirow[t]{2}{*}{$\geq 75$ percentiles } & $0.99(0.67-1.48)$ & 0.984 & $\leq 4 \mathrm{~h}$ & 1 & \\
\hline & & & $>4 \mathrm{~h}$ & $0.96(0.73-1.28)$ & 0.790 \\
\hline Systolic blood pressure $(\mathrm{SD}=10 \mathrm{mmHg})$ & $1.11(1.04-1.19)$ & 0.001 & Siesta time/day (SD = 15 min) & $1.08(1.01-1.15)$ & 0.020 \\
\hline \multicolumn{3}{|l|}{ Dyslipidemia } & \multicolumn{3}{|c|}{ Each of the following obesity-related measurements: } \\
\hline No & 1 & & Waist-hip ratio $(S D=0.07)$ & $1.21(1.03-1.41)$ & 0.019 \\
\hline Yes & $1.48(1.04-2.09)$ & 0.027 & Waist circumference $(\mathrm{SD}=7 \mathrm{~cm})$ & $1.12(0.98-1.27)$ & 0.086 \\
\hline CDKL2A-rs10811661 per copy of T allele & $1.23(1.03-1.46)$ & 0.022 & Hip circumference $(S D=7 \mathrm{~cm})$ & $1.01(0.85-1.21)$ & 0.873 \\
\hline TCF7L2-rs7903146 per copy of T allele & $1.13(0.64-2.01)$ & 0.676 & Body mass index $\left(\mathrm{SD}=0.25 \mathrm{~kg} / \mathrm{m}^{2}\right)$ & $1.12(0.99-1.28)$ & 0.079 \\
\hline IRS1-rs1801278 per copy of G allele & $1.01(0.57-1.79)$ & 0.967 & Body fat $(\mathrm{SD}=\%)$ & $1.22(0.90-1.66)$ & 0.206 \\
\hline INSR-rs3745551 per copy of G allele & $1.05(0.86-1.27)$ & 0.648 & & & \\
\hline FTO-rs9939609 per copy of A allele & $0.98(0.79-1.22)$ & 0.852 & & & \\
\hline
\end{tabular}


Table 3 The most significant independent predictors of prediabetes

\begin{tabular}{llccc}
\hline Variable & Unit & Coefficient & Odds ratio $(95 \% \mathrm{Cl})$ & $P$-value \\
\hline Waist to hip ratio & 0.07 & 0.224 & $1.25(1.10-1.42)$ & $<0.0001$ \\
Systolic blood pressure & $10 \mathrm{mmHg}$ & 0.124 & $1.13(1.07-1.20)$ & $<0.0001$ \\
Dyslipidemia & $0=$ no, 1 = yes & 0.453 & $1.57(1.15-2.14)$ & 0.004 \\
Residence & $0=$ rural, 1 = urban & 1.038 & $1.93(2.82-4.14)$ & $<0.0001$ \\
CDKN2A-rs10811661 & Number of T allele & 0.201 & $1.22(1.04-1.44)$ & 0.017 \\
Intercept & & -6.581 & - & $<0.0001$
\end{tabular}

$P$-value by multivariate logistic regression

residence, waist-hip ratio, and systolic blood pressure, dyslipidemia and CDKN2A-rs10811661 polymorphism was 0.646 (95 \% CI: $0.614-0.677, P<0.0001$ ). Adding the genetic marker to the clinical covariates improved the area under ROC curve slightly from 0.637 to $0.646(P<0.019$, Wilcoxon Signed Ranks Test) (Fig. 1).

\section{Discussion}

Of the 5 candidate SNPs tested for association, we found that the CDKN2A-rs10811661 polymorphism was significantly associated with prediabetes in a Vietnamese population, independent of obesity-related traits, considering the influence of the socio-economic status and lifestyle factors. The association of the CDKN2A-rs10811661 polymorphism with $\mathrm{T} 2 \mathrm{D}$ was initially reported in White populations [18-20], and subsequently replicated in Asian populations [21-23]. The CDKN2A-rs10811661 polymorphism was significantly associated with T2D in Japaneses $(\mathrm{OR}=1.25,95 \% \mathrm{CI}=1.08-1.45, P=0.0024)$ [22], and in Indians $(\mathrm{OR}=1.37,95 \% \mathrm{CI}=1.18-1.59, P=5.1 \mathrm{E}-05)$ [24]. In Chinese populations, the CDKN2A-rs10811661 polymorphism was associated with increased risk in both prediabetes $(\mathrm{OR}=1.23,95 \% \mathrm{CI}=1.11-1.36)$ and $\mathrm{T} 2 \mathrm{D}$ $(\mathrm{OR}=1.46,95 \% \mathrm{CI}=1.01-2.11)$ in a case-control study and confirmed in a prospective study that the risk allele of rs10811661 increased the risk of incident T2D by $94 \%$ [25]. Moreover, in GWA studies in Asians, the variant was associated with T2D in East Asians (Han Chinese and Japanese) $(\mathrm{OR}=1.23,95 \% \mathrm{CI}=1.18-1.29, P=1.43 \mathrm{E}-18)$ [26], and a large multi-center GWA study replicated the

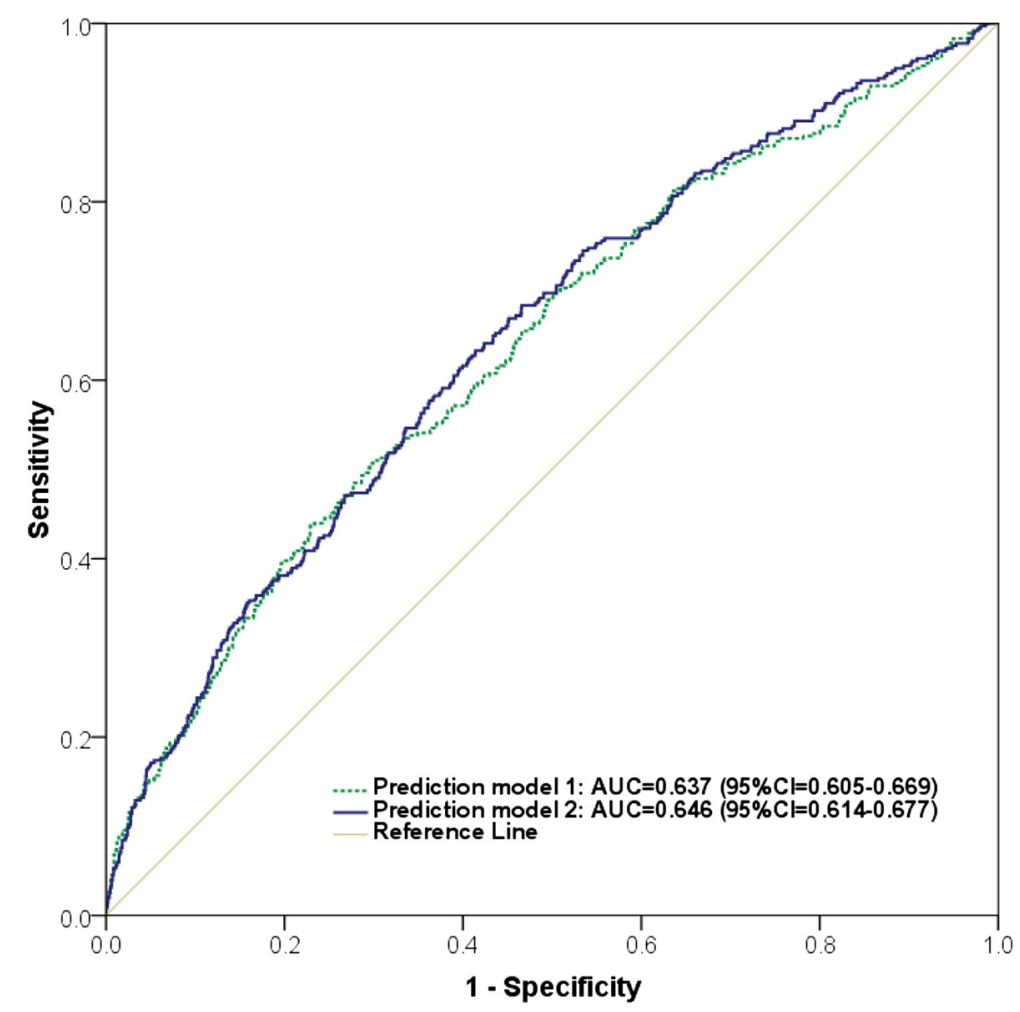

Fig. 1 ROC curvers for the prediction models on the number of risk allele of CDKN2A-rs10811661, residence, waist-hip ratio, systolic blood pressure, and dyslipidemia in model 2 and model 1 without genetic marker 
association in both East Asians $(\mathrm{OR}=1.25,95 \% \mathrm{CI}=$ 1.17-1.32, $P=6.3 \mathrm{E}-13)$ and South Asians $(\mathrm{OR}=1.20,95 \%$ $\mathrm{CI}=1.11-1.31, P=1.4 \mathrm{E}-05) \quad$ [27]. These studies showed that the effect of the variant in CDKN2A gene seemed slightly higher in T2D compared to prediabetes in the present study (OR $=1.22,95 \% \mathrm{CI}=1.04-1.44, P=0.017)$. On the other hand, this polymorphism was not associated with prediabetes in German people [28]. Given the multifactorial pattern of prediabetes, the contribution of the CDKN2A-rs10811661 polymorphism varies among populations depending on the socio-economic status, lifestyle factors, genetic background, and risk-factor profile of each population [29].

There were many factors influencing the association between the CDKN2A-rs10811661 polymorphism and prediabetes, including bias selection of subjects, confounding factors such as socio-economic condition, and lifestyle factors. The bias selection in the study was controlled since the subjects were recruited from the population - based screening survey with a sample size representative of all prediabetic cases and normoglycemic controls in the general population. Moreover, given the multifactorial nature of prediabetes, the association in our study was investigated in several analysis models, which considered the various factors including sex, age, systolic blood pressure, obesity - related traits (BMI, WC, WHR, and body fat percentage), socio-economic patterns (occupation, education level, residence, marital status, income level), and lifestyle factors (smoking, alcohol consumption, leisure time spent sitting, watching TV, and siesta). Thereby, the statistically significant association between the CDKN2A-rs10811661 polymorphism and prediabetes was found to be independent of the traditional risk factors.

Regarding the allele and genotype frequencies of the CDKN2A-rs10811661 polymorphism, we found that the risk $\mathrm{T}$ allele frequency was $57.6 \%$, and the frequencies of CC, CT, and TT genotypes were 18.9, 46.9, and $34.2 \%$, respectively in the total sample. The allele and genotype frequencies in our sample were similar to those in Asian populations (Han Chinese: $57 \%$, Japanese: $52.4 \%$ ) and different from those in European (77.8-80.1\%) and African (89-98.2 \%) populations based on HapMap data [30].

Being obesity, which is associated with insulin resistance and dysfunction of beta cell, is one of the most important risk factors for the development of prediabetes [31]. Among obesity-related traits, WHR was recognized to be the most significantly associated with prediabetes in our population. In the present study, the association between the CDKN2A-rs10811661 polymorphism and prediabetes was consistently significant when adding each of the obesity - related traits in the analysis models including age, gender, systolic blood pressure, socio-economic status and lifestyle factors, indicating the direct effect of the CDKN2A-rs10811661 polymorphism on prediabetes, independently of the obesity-related traits.

In terms of predictors of prediabetes, few genetic studies have been reported although the importance of prediabetes has been underscored. The present data showed an increased prediabetes risk with an additive effect of the alleles of $C D K N 2 A$-rs10811661 (OR per $\mathrm{T}$ allele $=1.22$, $95 \% \mathrm{CI}=1.04-1.44, P=0.017$ ). Our finding supports the association of the CDKN2A-rs10811661 polymorphism with prediabetes reported in previous case-control studies in Asian populations [22, 23, 25, 28]. Moreover, the predictive effect of the CDKN2A-rs10811661 polymorphism on the incident T2D was also confirmed in a 3.5 year follow-up study [28]. These findings can be explained by the evidences that a reduced insulin release was observed for the CDKN2A-rs10811661 T-allele after both oral and intravenous glucose challenges [20] and that the SNP was significantly associated with early-phase insulin release [32]. Among the independent risk factors for prediabetes, WHR, dyslipidemia, and systolic blood pressure demonstrated the strongest effects in our findings, which is in agreement with previous studies [33-35]. Adding the genetic marker to the clinical covariates in our study improved slightly the area under the receiver operating characteristic curve from 0.637 to $0.646(P<0.019)$, indicating that the studied variant had a small effect on prediabetes.

Indeed, some advantages could be highlighted in this study. Since this is a large population-based study in the Red River Delta region, Vietnam, the findings of the study will be interpreted for general population of this region in both genetic pattern and risk factor profile. The studied population could be considered as a homogeneous sample of the Kinh ethnic adults aged 40-64 years in a rural province without other ethnic admixtures. Prediabetes including IFG and/or IGT was determined using fasting plasma glucose level and oral glucose tolerance test with $75 \mathrm{~g}$ glucose. This method has been widely accepted and frequently referred as the "gold standard" for diagnosis of prediabetes. However, several limitations should be noted in this study. First, the limitation of the cross-sectional study design does not allow for conclusions of the causal relationships. Next, among many candidate SNPs have been proposed to be associated with T2D and prediabetes, the present study was only interested in 5 SNPs in genes related to insulin pathway, and thereby the studied genetic variant had a small effect on prediabetes despite statistical significance. Lastly, the area under ROC curve of 0.646 shows the poor power of prediction of the model.

\section{Conclusions}

These data demonstrate that the CDKN2A-rs10811661 polymorphism, waist-hip ratio, systolic blood pressure, 
and dyslipidemia were significantly associated with the increased risk of prediabetes in a Vietnamese population. The association remains consistent after adjustment for age, gender, socio-economic status, and lifestyle-related factors. Because of the small contribution of the single $C D K N 2 A-r s 10811661$ polymorphism, it is necessary to conduct a large-scale prospective study on prediabetes and T2D in Vietnamese population.

\section{Additional files}

Additional file 1: Table S1. Methods for genotyping CDKN2A, FTO,

INSR, IRS1, and TCF7L2 polymorphisms. (DOCX $37 \mathrm{~kb}$ )

Additional file 2: Table S2. Associated factors of prediabetes in middle-aged population in univariate logistic regression analysis. (DOCX $39 \mathrm{~kb}$ )

Additional file 3: Table S3. Analysis of the best-fit model for individual SNPs of candidate genes for prediabetes. (DOCX $23 \mathrm{~kb}$ )

Additional file 4: Figure S1. Analysis Bayesian Model Averaging analysis to cross-validate the final model. (DOCX $67 \mathrm{~kb}$ )

\section{Abbreviations}

BMI: Body mass index; Cl: Confidence interval; DBP: Diastolic blood pressure HC: Hip circumference; HDL-C: High-density lipoprotein cholesterol; IGT: Impaired glucose tolerance; IFG: Impaired fasting glucose; LDL-C: Lowdensity lipoprotein cholesterol; OGTT: Oral glucose tolerance test; OR: Odds ratio; RFLP: Restriction fragment length polymorphism; SBP: Systolic blood pressure; TC: Total cholesterol; T2D: Type 2 diabetes; TG: Triglycerides; WC: Waist circumference; WHR: Waist-hip ratio.

\section{Competing interests}

The authors declare that they have no competing interests.

\section{Authors' contributions}

TQB: Conceptualization of the study, study design, proposal writing, data collection, data analysis, discussion and editing of the final draft for publication. NTTT, PTP: Conceptualization of the study, data collection, data analysis, discussion and editing of the final draft for publication. BTN, TTHN: data collection, data analysis, discussion, and editing of the final draft for publication. All authors approved the final draft of this article prior to submission.

\section{Acknowledgments}

The authors would like to thank Dr. Dang Dinh Thoang, Dr. Pham Van Thang, and Mrs. Nguyen Minh Thai for kindly helps and supports. We acknowledge the health staff of the Ha Nam Center for Preventive Medicine for their cooperation and assistance.

This study was supported by Vietnam's National Foundation for Science and Technology Development (NAFOSTED), grant no. 106.09-2012.04 from the Ministry of Science and Technology, Vietnam.

\section{Author details}

${ }^{1}$ National Institute of Hygiene and Epidemiology, 1 Yersin, Hanoi 112800 , Vietnam. ${ }^{2}$ Hanoi National University of Education, 136 Xuan Thuy Street, Hanoi, Vietnam. ${ }^{3}$ National Institute of Nutrition, 48B Tang Bat Ho Street, Hanoi 112807, Vietnam.

Received: 16 April 2015 Accepted: 21 August 2015

Published online: 03 September 2015

\section{References}

1. Kuzuya T, Nakagawa S, Satoh J, Kanazawa Y, Iwamoto Y, Kobayashi M, et al. Report of the Committee on the classification and diagnostic criteria of diabetes mellitus. Diabetes Res Clin Pract. 2002;55(1):65-85.

2. Nathan DM, Davidson MB, DeFronzo RA, Heine RJ, Henry RR, Pratley R, et al. Impaired fasting glucose and impaired glucose tolerance: implications for care. Diabetes Care. 2007;30(3):753-9.
3. Nichols GA, Hillier TA, Brown JB. Progression from newly acquired impaired fasting glusose to type 2 diabetes. Diabetes Care. 2007;30(2):228-33.

4. Barr EL, Zimmet PZ, Welborn TA, Jolley D, Magliano DJ, Dunstan DW, et al. Risk of cardiovascular and all-cause mortality in individuals with diabetes mellitus, impaired fasting glucose, and impaired glucose tolerance: the Australian Diabetes, Obesity, and Lifestyle Study (AusDiab). Circulation. 2007;116(2):151-7.

5. Buysschaert M, Medina JL, Bergman M, Shah A, Lonier J. Prediabetes and associated disorders. Endocrine. 2014;1-23. doi:10.1007/s12020-014-0436-2.

6. Tuso P. Prediabetes and lifestyle modification: time to prevent a preventable disease. Perm J. 2014;18(3):88-93.

7. Chan JC, Malik V, Jia W, Kadowaki T, Yajnik CS, Yoon KH, et al. Diabetes in Asia: epidemiology, risk factors, and pathophysiology. JAMA. 2009;301:2129-40.

8. Weber MB, Oza-Frank R, Staimez LR, Ali MK, Narayan KM. Type 2 diabetes in Asians: prevalence, risk factors, and effectiveness of behavioral intervention at individual and population levels. Annu Rev Nutr. 2012;32:417-39.

9. Sladek R, Rocheleau G, Rung J, Dina C, Shen L, Serre D, et al. A genomewide association study identifies novel risk loci for type 2 diabetes. Nature. 2007:445:881-5.

10. Basile KJ, Johnson ME, Xia Q, Grant SF. Genetic susceptibility to type 2 diabetes and obesity: follow-up of findings from genome-wide association studies. Int J Endocrinol. 2014:2014:769671. doi:10.1155/2014/769671.

11. Saxena R, Elbers CC, Guo Y, Peter I, Gaunt TR, Mega JL, et al. Large-scale gene-centric meta-analysis across 39 studies identifies type 2 diabetes loci. Am J Hum Genet. 2012;90:410-25.

12. Quang Binh T, Tran Phuong P, Thi Nhung B, Dinh Thoang D, Van Thang P, Khanh Long $T$, et al. Prevalence and correlates of hyperglycemia in a rural population, Vietnam: implications from a cross-sectional study. BMC Public Health. 2012;12:939.

13. Expert Panel on Detection, Evaluation, and Treatment of High Blood Cholesterol in Adults. Executive Summary of the Third Report of the National Cholesterol Education Program (NCEP) Expert Panel on Detection Evaluation, and Treatment of High Blood Cholesterol in Adults (Adult Treatment Panel III). JAMA. 2001;285:2486-97. doi:10.1001/jama.285.19.2486

14. World Health Organization. Definition and diagnosis of diabetes mellitus and intermediate hyperglycemia: report of a WHO consultation. Geneva: World Health Organization; 2006.

15. Wangkumhang P, Chaichoompu K, Ngamphiw C, Ruangrit U, Chanprasert J, Assawamakin A, et al. WASP: a Web-based Allele-Specific PCR assay designing tool for detecting SNPS and mutations. BMC Genomics. 2007:8:275. doi:10.1186/1471-2164-8-275

16. Solé X, Guinó E, Valls J, Iniesta R, Moreno V. SNPStats: a web tool for the analysis of association studies. Bioinformatics. 2006;22(15):1928-9.

17. Team RC. R: A language and environment for statistical computing. R Foundation for Statistical Computing, Vienna, Austria. 2015. http://www.R-project.org/.

18. Scott LJ, Mohlke KL, Bonnycastle LL, Willer CJ, Li Y, Duren WL, et al. A genome-wide association study of type 2 diabetes in Finns detects multiple susceptibility variants. Science. 2007;316(5829):1341-5.

19. Grarup N, Rose CS, Andersson EA, Andersen G, Nielsen AL, Albrechtsen A, et al. Studies of association of variants near the HHEX, CDKN2A/B, and IGF2BP2 genes with type 2 diabetes and impaired insulin release in 10,705 Danish subjects: validation and extension of genome-wide association studies. Diabetes. 2007;56(12):3105-11.

20. Zeggini $\mathrm{E}$, Weedon MN, Lindgren CM, Frayling TM, Elliott KS, Lango $\mathrm{H}$, et al. Replication of genome-wide association signals in UK samples reveals risk loci for type 2 diabetes. Science. 2007;316:1336-41.

21. Ng MCY, Park KS, Oh B, Tam CHT, Cho YM, Shin HD, et al. Implication of genetic variants near TCF7L2, SLC30A8, HHEX, CDKAL1, CDKN2A/B, IGF2BP2, and FTO in type 2 diabetes and obesity in 6,719 Asians. Diabetes. 2008:57:2226-33.

22. Omori S, Tanaka Y, Takahashi A, Hirose H, Kashiwagi A, Kaku K, et al. Association of CDKAL1, IGF2BP2, CDKN2A/B, HHEX, SLC30A8, and KCNJ11 with susceptibility to type 2 diabetes in a Japanese population. Diabetes. 2008;57:791-5.

23. Wu Y, Li H, Loos RJ, Yu Z, Ye X, Chen L, et al. Common variants in CDKAL1, CDKN2A/B, IGF2BP2, SLC30A8, and HHEX/IDE genes are associated with type 2 diabetes and impaired fasting glucose in a Chinese Han population. Diabetes. 2008;57(10):2834-42.

24. Ganesh C, Charles US, Rubina T, Seema B, Smita RK, Anubha M, et al Impact of common variants of PPARG, KCNJ11, TCF7L2, SLC30A8, HHEX, CDKN2A, IGF2BP2 and CDKAL1 on the risk of type 2 diabetes in 5.164 Indians. Diabetes. 2010;59:2068-74. 
25. Xu M, Bi Y, Xu Y, Yu B, Huang Y, Gu L, et al. Combined effects of 19 common variations on type 2 diabetes in Chinese: results from two community-based studies. PLoS One. 2010;5(11):e14022. doi:10.1371/journal.pone.001402221103332.

26. Hara K, Fujita H, Johnson TA, Yamauchi T, Yasuda K, Horikoshi M, et al. Genome-wide association study identifies three novel loci for type 2 diabetes. Hum Mol Genet. 2014;23(1):239-46. doi:10.1093/hmg/ddt399.

27. DIAbetes Genetics Replication And Meta-analysis (DIAGRAM) Consortium, Asian Genetic Epidemiology Network Type 2 Diabetes (AGEN-T2D) Consortium, South Asian Type 2 Diabetes (SAT2D) Consortium, Mexican American Type 2 Diabetes (MAT2D) Consortium, Type 2 Diabetes Genetic Exploration by Nex-generation sequencing inmuylti-Ethnic Samples (T2D-GENES) Consortium, et al. Genome-wide trans-ancestry meta-analysis provides insight into the genetic architecture of type 2 diabetes susceptibility. Nat Genet. 2014;46(3):234-44. doi:10.1038/ng.2897.

28. Zyriax B-C, Salazar R, Hoeppner W, Vettorazzi E, Herder C, Windler E. The association of genetic markers for type 2 diabetes with prediabetic status - cross-sectional data of a diabetes prevention trial. PLoS One. 2013;8(9):e75807. doi:10.1371/journal.pone.0075807.

29. Adeyemo A, Rotimi C. Genetic variants associated with complex human diseases show wide variation across multiple populations. Public Health Genomics. 2010;13:72-9.

30. Sherry ST, Ward M and Sirotkin K. dbSNP-Database for single nucleotide polymorphisms and other classes of minor genetic variation. Genome Res. 1999;9:677-9.

31. Kahn BB, Flier JS. Obesity and insulin resistance. J Clin Invest. 2000;106(4):473-81.

32. Stančáková A, Kuulasmaa T, Paananen J, Jackson AU, Bonnycastle LL, Collins FS, et al. Association of 18 confirmed susceptibility Loci for type 2 diabetes with indices of insulin release, proinsulin conversion, and insulin sensitivity in 5,327 nondiabetic Finnish men. Diabetes. 2009;58(9):2129-36.

33. Khambalia A, Phongsavan P, Smith BJ, Keke K, Dan L, Fitzhardinge A, et al. Prevalence and risk factors of diabetes and impaired fasting glucose in Nauru. BMC Public Health. 2011;11:719. doi:10.1186/1471-2458-11-719.

34. Soriguer F, Goday A, Bosch-Comas A, Bordiú E, Calle-Pascual A, Carmena R, et al. Prevalence of diabetes mellitus and impaired glucose regulation in Spain: The Di@bet.es Study. Diabetologia. 2012;55:88-93.

35. Díaz-Redondo A, Giráldez-García C, Carrillo L, Serrano R, García-Soidán F, Artola $\mathrm{S}$, et al. Modifiable risk factors associated with prediabetes in men and women: a cross-sectional analysis of the cohort study in primary health care on the evolution of patients with prediabetes (PREDAPS-Study). BMC Fam Pract. 2015;16:5. doi:10.1186/s12875-014-0216-3.

\section{Submit your next manuscript to BioMed Central and take full advantage of:}

- Convenient online submission

- Thorough peer review

- No space constraints or color figure charges

- Immediate publication on acceptance

- Inclusion in PubMed, CAS, Scopus and Google Scholar

- Research which is freely available for redistribution 